NASA Technical Memorandum 79056

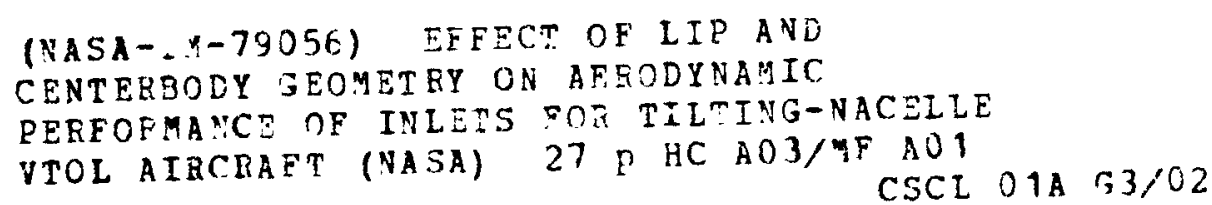

N79-14799

\title{
EFFECT OF LIP AND CENTERBODY \\ GEOMETRY ON AERODYNAMIC \\ PERFORMANCE OF INLETS FOR \\ TILTING-NACELLE VTOL AIRCRAFT
}

Richard R. Burley

Lewis Research Center

Cleveland, Ohio

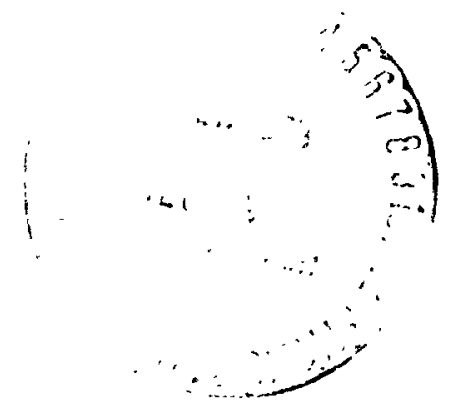

TECHNICAL PAPER to be presented at the

Seventeenth Aerospace Sciences Meeting

sponsored by the American Institute of Aeronautics

and Astronautics

New Orleans, Louisiana, January 15-17, 1979 


\title{
EFEECT OF LIP AND CENTERBODY GEOMETRY ON
}

\author{
AERODT NAMIC PERFORMIANCE OF INLETS FOR
}

TILTING-NACELLE VTOL AIRCRAFT

by Richard R. Burley

National Aeronautics and Space Administration

Lewis Research Center

Cleveland, Ohio

\begin{abstract}
Inlets for tilt-nacelle VTOL aircraft must operate over a wide range of incidence angles and engine veight flows without internal flow separation. Wind tunnel tests of scale model inlets were conducted to evaluate the effectiveness of three geometric variables to provide this capability. Increasing the lip contraction ratio increased the separation angle at all engine weight flows. The optimum axial location of the centerbody occurred when its leading edge was located just downstream of the inlet lip. Compared with a short centerbody, the optimum location of the centerbody resulted in an increase in separation angle at all engine weight flows. Decreasing the lip major-to-minor-axis ratio increased the separation angle at the lower engine weight flows.
\end{abstract}

\section{INTRODUCTION}

Engine inlets for tilt-nacelle VTOL aircraft must operate efficiently over a wide range of flight speeds, engine weight flows, and incidence angles. Large incidence angles are imposed on the engine inlet because the nacelles are required to rotate to a vertical position during takeoff and landing maneuvers. As the incidence angle increases, the tendency for the inlet internal flow to separate a!so increases. If flow separation occurs, the resulting fan face distortion couid be large enough to cause excessively high fan blade stresses and might also cause core-compressor stall. Thus, it is important that the flow remain attached at the high incidence angles required of inlets for tilt-nacelle VTOL airc aft.

The NASA Lewis Research Center is currently engaged in a research program to evaluate the effectiveness of several geometric design variables to help achieve the high incidence angle capability required of these inlets. One variable being considered is the internal lip contraction ratio. Analytical studies 
(refs 1 to 3) indicate that increasing the contraction ratio is very berieficial. Experimental results (refs. 4 and 5 ) are available only for inlets with a maximum contraction ratio of 1.56 . However, inlets applicable to tilt-nacelle VTOL aircratt. will operate to very high incidence angles and, consequently, might require contraction ratios greater than 1.56

A second design variable being considered is the internal lip major-tominor-axis ratio. An analytical study (ref. 3) indicates that decreasing this ratio might he effective at the lower throttle settings but no experimental results are available.

A third variable being considered is the location of the centerbody within the inlet coxil. Some preliminary experimental results for a few axial locations (refs. 6 and 7) indicate that this variable is important. But the most effective location remains to be determined.

This paper presents the results of an experimental investigation to evaluate the effectiveness of these three geometric design variables to provide the high incidence angle capability required by inlets on tilt-nacelle VTOL aircraft. The effectiveness of increasing the internal lip contraction ratio was evaluated using inlets with contraction ratios of $1.46,1.65$, and 2.0. For completeness, results are also presented for a lip contraction ratio of 1.37 from reference 5. The internal contour of these lips was an ellipse with a major-to-minor-axis ratio of 2 . The effectiveness of decreasing the internal lip major-to-minor-axis ratio was evaluated using inlets with ratios of 2 to 1 and 1.5 to 1 . The contraction ratio of these lips was 1.46 . The optimum axial location of the centerbody was evaluated for an inlet with a contraction ratio of 1.46 and a major-to-minoraxis ratio of 2 to 1 . All of these inlets had a diffuser exit diameter (equivalent to a fan diameter) of 30.48 centimeters.

The inlets were tested in the Lewis Research Center's 2.74- by 4.58-meter low speed wind tunnel. The tests were conducted using a vacuum system to induce inlet airflow. Results are presented at a tunnel airflow velocity of 41 meters per second for incidence angles from $0^{\circ}$ to $150^{\circ}$. Inlet average throat Mach number was varied between 0.30 and 0.79 . Measurements were made to determine inlet total-pressure recovery, steady-state total-pressure distortion, and incidence angle at flow separation.

\section{SYMBOLS}
A area
a naajof axis of internal lip (fig. 2)
b minor axis of internal lip (fig. 2) 


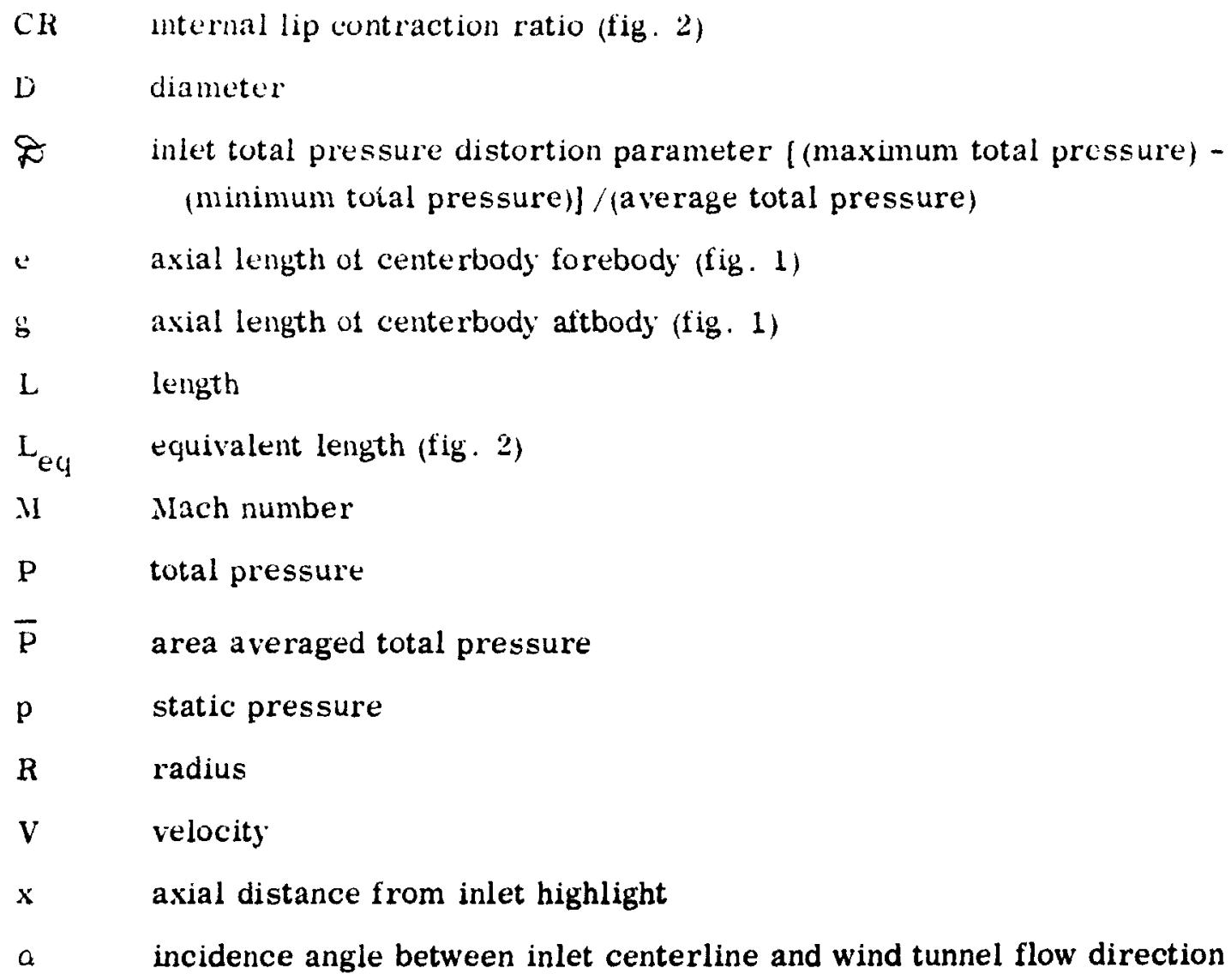
(fig. 1)

0 inlet diffuser wall angle

$\lambda$ diffuser equivalent conical half-angle, $\tan ^{-1}\left(\frac{\sqrt{\frac{A_{\text {max }}}{\pi}}-\sqrt{\frac{A_{\text {min }}}{\pi}}}{L_{e q}}\right)$

$\psi \quad$ circumferential position (fig. 3)

Subscripts :

cb centerbody

d diffuser

dist distortion

e diffuser exit

he highlight

hub hub 


$\begin{array}{ll}\text { LE } & \text { leading edge } \\ \text { max } & \text { maximum } \\ \text { min } & \text { minimum } \\ \imath & \text { throat } \\ \text { tup } & \text { tip } \\ 0 & \text { free stream }\end{array}$

\section{APPARATLS AND PROCEDLRE}

\section{Inlet Configurations}

The inlet numenclature used is shown in figure 1 and the three geometric variables investigated are shown in figure 2 . One variable was the internal lip contraction ratio, defined as the ratio of the highlight area to the throat area $\left(D_{h i} / D_{t}\right)^{2}$. Four contraction ratios were evaluated, 1.37, 1.46, 1.05, and 2.00 (fig. 2(a)). The internal contour of these lips was an ellipse with a majorto-minor-axis ratio, $a / b$, of 2.0 . The second variable was the $a / b$ ratio. Two a/b ratios were investigated, 2.0 and 1.5 (fig. 2 (b)) for an inlet lip with a contraction ratio of 1.46 . The third variable was the axial location of the centerbody within the inlet cowl. This location is defined as the axial distance from the inlet highlight to the centerbody leadirg edge divided by the inlet length, $(x / L)_{L E}$. Centerbody axial locations varied from $(x / L)_{L E}=-0.123$ to 0.507 (see fig. $2(c-1)$ ). Negative values indicate that the leading edge of the centerbody is ahead of the inlet highlight, that is, outside of the cowl. The inlet lip had a contraction ratio of 1.46 and an $a / b$ ratio of 2.0 .

The axial location of the centerbody effected the diffuser equivalent conical half-angle (fig. $2(c-2)$ ). With the centerbody fully extended, $(x / L)_{L E}=-0.123$, the half-angle was $5.4^{\circ}$. As the centerbody was retracted to $(x / L)_{L E}=0.2$, the half-angle decreased to a value of $3.5^{\circ}$. As the centerbods was retracted further, two half-angles were defined. One is based on the first set of minimum and maximum areas that occur aft of the cowl highlight $\left(A_{\min }\right.$ and $A_{\max _{1}}$ in fig. $2(c-2)$ ). This half-angle increased to a value of $7.6^{\circ}$ when the centerbods was completely retracted. The second equivalent conical half-angle is based on the second set of minimum and maximum areas that occur aft of the cowl highlight $\left(A_{\min _{2}}\right.$ and $A_{\text {max }_{2}}$ in fig. 2(c-2)). It decreased to a value of about $2^{\circ}$ when the centerbody was completely retracted.

The geometry of the diffusers and centerbodies is shown in table 1 . One diffuser and centerbody were used for the investigation of contraction ratios 
and $a / b$ ratios The diffuse $r$ had an equivalent conical half-angle of $29^{\circ}$ and a maximum wall angle of $8.7^{\circ}$ occurring at the midpoint of the diffuser. The centerbody had an elliptical shape $v^{\prime} \mathrm{j}^{\mathrm{t}} \mathrm{h}$ its leading edge located at $(x / L){ }_{L E}=$ $0.6 t$.

A different diffuser and centerbody were used for the investigation of centerbody axial location. This configuration was used previously for sonic unlet tests (ref. 7). The diffuser had a maximum wall angle of $10.7^{\circ}$ occurring well torward of the diffuser midpoint The equivalent conical half-angle of this diffuser, as previously shown in figure $2(\mathrm{c}-2)$, varied between $3.5^{\circ}$ and $76^{\circ}$. The centerbody had a bulbous shape w'ith i's maximum diameter $12 . \bar{j}$ percent preater than its hub diameter at the diffuser exit. The location of the leading adge of the centerbody, as mentioned, varied between $(x / L)_{L E}=-0.123$ and 0.507

The bulbous centerbody shape had been selected for the sonic inlet tests reported in reference $i$ This shape was required to provide a constant inlet throat Nach number over a wide range of inlet weight flows by translating the centerbody to provide the appropriate inlet throat area.

\section{Instrumentation}

Inlet instrunentation is shown in figure 3 Two axial rows of 20 static pressure taps each were located on the inlet extunding from the highlight to the diffuser exit. One row was located on the windward side $\left(\psi=0^{\circ}\right)$ of the inlet and the other was located on the leeward side $\left(\psi-180^{\circ}\right)$. For this paper, only the windward side distribution will be presented since the most severe flow conditions occur on this side.

To detect flow separation from the windward side lip, a static pressure tap halfway between the highlight and throat was used. Its value was displayed on line during the tests. More will he said about this later.

Diffuser exit total pressure measurements were made using both hub and tip boundary layer rakes as well as rakes spanning the entire annulus. Eight full-span total pressure rakes, equally spaced circumferentially, were used with six equal-area-weighted tubes per rake. The 16 boundary layer rakes (eight at the hub and eight at the tip) each contained five total pressure tubes.

To detect flow separation in the diffuser, a total pressure tube and a static pressuse tap were located in the diffuser exit plane $3^{\circ}$ from the windward side as illustrated in figure 3 . The total pressure tube was 0.48 centimeter from the outer wall. The difference tatween this total pressure and the wall static pressure $\Delta P_{d}$ was displayed on line during the test. More will be sald about this later. 
An indication of total pressure distortion was obtained using two total pressure tubes from the diffuser exit rakes; one tube was from the rake on the windward side $\left(\psi=0^{\circ}\right)$ and the other tube was from the rake on the leeward side $\left(\psi=180^{\circ}\right)$ as shown in figure 3 . This $\Delta P_{\text {dist }}$ value was also displayed on line during the tests.

Inlet total pressure recovery was computed using all measured total pressures, including boundary layer rakes, with the appropriate area weighting terms. In computing inlet total pressure distortion, however, boundary layer measurements taken closer to the wall than the nearest tube on the six element rakes were omitted. Inlet one-dimensional throat Mach number was computed using the inlet weight flow measured by a venturi located downstream in the flow duct and the geometric throat area assuming uniform flow.

\section{Facility}

The tests were conducted in the Lewis Research Center's 2.74- by 4.58meter (9- by 15-ft) V/STOL wind tunnel. The test section is shown in figure 4 with a high contraction ratio inlet model installed. A vacuum system was used in place of a fan to induce inlet flow. Inlet incidence angle was remotely varied by a turntable on which the test model was mounted. For the present tests, the maximum angle-of-attack was $150^{\circ}$. A more detailed description of the facility is given in reference 8 .

\section{Procedure}

The inlets were tested at static conditions and at free-stream velocities of 41 and 61 meters per second (80 and 120 knots). For this paper, results will be presented only at the free-stream velocity of 41 meters per second. The inlet average throat Mach number was varied between 0.30 and 0.79.

The data recorded to define the incidence angle at internal flow separation were obtained by first setting the tunnel velocity and the inlet alrflow. On line data were then recorded as the incidence anglo was increased continuously from zero at approximately $2^{\circ}$ per second.

The data reoorded at discrete angles were obtained by setting tunnel velooity and in it weight flow whlle at $0^{\circ}$ incidence angle. Date were then recorded and the incidence angle was increased to the next value. Data were again recorded and the procedure repented. 


\section{RESULTS AND DISCUSSION}

This section hegins with a discussion of how internal flow separation was detected. Then the effect of each of the three geometric variables on inlet aerodynamic performance is presented. Finally, a comparison of these three inlet configurations is made.

\section{Detection of Internal Flow Separation}

As mentioned in the APPARATUS AND PROCEDURE section, measurements were made to detect internal flow separation on the lip as well as in the diffuser. An example of the basic experimental data used to identify lip and diffuser flow separation is shown in figures 5 (a) and (b), respectively. The data are for a constant free-stream velocity and a constant inlet throat Mach number.

The variation in Jip static pressure with incidence angle is shown in figure 5(a-1). As the incidence angle increases, the lip static pressure continuously decreases up to some angle where an abrupt increase occurs indicating flow separation.

Typical cowl axial static pressure distributions for attached and separated flow conditions are shown in figure $5(a-2)$. The distribution for attached flow shows a smooth continuous diffusion to the diffuser exit. In comparison, the distribution for separated flow is relatively flat showing an absence of diffusion on the lip starting at $x / L=0.15$ (the lip extends to $x / L=0.17$ ).

The variation in diffuser exit total minus static pressure with incidence angle is shown in figure 5(b-1). As the incidence angle increases, the diffuser exit $\Delta \mathrm{P}_{\mathrm{d}}$ decreases slightly (indicating a thickening of the boundary layer) until the flow separates and the $\Delta P_{\mathrm{d}}$ abruptly decreases to zero.

Typical radial total pressure profiles at the diffuser exit on the windward side for attached and separated flow conditions are shown in figure 5(b-2). The profile for attached flow shows the pressure increasing continuously from its static value at the cowl (tip) until the free-stream value is achieved at about 70 percent of the duct height from the hub. In comparison, the profile for separated flow shows pressures lower than the static value at the cowl (tip) that extend over the outer half of the duct height indicating separated flow.

\section{Effect of Contraction Ratio}

The effect of increasing the contraction ratio on the incidence angle at which internal flow separation occurred is shown in figure 6 . The results are 
presented as a function of inlet, throat Mach number for contraction ratios of 1. 37, 1 46, 1 65. and 2.0. Each curve is the houndary between attached and separated fluw. Over the entire range of throat Mach numbers, increasing the contraction ratio increased the separation angle. For a contraction ratio of 1.37, the maximum value of this angle was $51^{\circ}$. For a contraction ratio of 2.0 , the maximum value was greater than $150^{\circ}\left(150^{\circ}\right.$ was the largest incidence angle that could be achieved in the facility).

Note that for three of the lip contraction ratios, 1.37, 1.46, and 1.65, the separation angle increases with increasing throat, Mach number to a maximum value that sccurs between throat Mach numbers of 0.6 and 0.7 and then decreases with further increases in throat Mach number. This behavior, as suggested in reference 5 , might be due to the appearance of shock-boundarylayer interaction at the higher throal Mach numbers where the flow adjacent to the surface achieves sonic velocity or greater.

It should also be noted that, when internal flow separation occurred it propagated instantaneously throughout the entire inlet. This can be seen by examining the behavior of the lip and diffuser separation detectors as a function of incidence angle. Traces of these are shown in figure 7 for a lip contraction ratio of 1.46 at a throat Mach number of 0.45. Also shown is the indicator of distortion described in the APPARATUS AND PROCEDURE section. Both the lip and diffuser separation indicators show an abrupt change at the same incidence angle $\left(57^{\circ}\right)$ indicating that the flow separatad on the lip and in the diffuser at essentially the same time. This type of separation resulted in a very abrupt increase in distortion as can be seen from the distortion indicator. The increase in distortion might be severe enough to cause excessively high fan blade stresses and/or the losses may be high enough to prevent attainment of the required thrust level, thus precluding the possibility of operating the fan in this separated flow region.

As mentioned, increasing the lip contraction ratio resulted in an increase in the incidence angle before flow separation occurred. An explanation for this behavior can be given by examining the axial distribution of surface static pressure shown in figure 8. Results are presented for attached flow at an incidence angle of $30^{\circ}$ and a throat Mach number of 0.45 .

For all contraction ratios, the static pressure decreases to a minimum value, which occurs on the lip, and then increases to the value at the diffuser exit $(x / L=1.0)$. Static pressure at the diffuser exit is the same for all contraction ratios for attached flow at a constant throat Mach number. But both the minimum static pressure and the slope of the static pressure profile immediately following the minimum static pressure (1.e., the initial adverse 
pressure gradient!, depend on the cont raction ratio. Both of these parameters have a large effer: on the tendency of the boundary laver to separate trom the internal iip of the inlet.

Increasing the contraction ratio increases the minimum value of the static pressure. This in turn reduce's the overall amount of diffusion required (diffuser exit static pressure ratio minus minimum static pressure ratio). The initial adverse pressure gradient also is reduced with increasing contraction ratio. The boundary layer is more likelv to remain attached to the inlet lip having the smallest overall amount of diffusion and al so the smallest initial adverse pressure gradient. Thus, increasing the contraction ratio is favorable to maintaining arrached flow. This is consistent with the results from figure 6 which showed that increasing the contraction ratio increaser the incidence angle at which flow separation occurred. It should be noted that, for attached flow, increasing the contraction ratio had litile effect on pressure recovery, which remained above 0.995 , and distortion level, which remained below 5 percent, for throat Mach numbers of 0.6 and less.

\section{Effect of Lip Major-to-Minor-Axis Ratio}

The effect of decreasing the lip major-to-minor-axis ratio, $\mathrm{a} / \mathrm{b}$, from 2.0 to 1.5 on the flow separation angle is shown in figure 9 . The results are presented for a lip contraction ratio of 1.46 as a function of throat Mach number at a free-stream velocity of 41 meters per second. Decreasing the $a / b$ ratio had a beneficial effect on the separation angle at low throat Mach numbers but an adverse effect at high throat Mach numbers. For throat Mach numbers below 0.57 , decreasing the $\mathrm{a} / \mathrm{b}$ ratio increased the separation angle by about $8^{\circ}$ at this free-stream velocity and for this inlet contraction ratio. For higher throat Mach number, however, decreasing the $a / b$ ratio decreased the separation angle by as much as $33^{\circ}$.

A possible explanation for this behavior can be given by examining the axial distribution of surface static pressure shown in figure 10. Results are presented for attached flow at a free-stream velocity of 41 meters per second and an incidence angle of $50^{\circ}$. For a throat Mach number of 0.45 (fig. 10(a)), the minimum value of the static pressure and thus the greater amount of overall diffusion required occurs for the inlet with $a / b=2.0$. The initial adverse pressure gradient also appears to be somewhat greater for this $a / b$ ratio. At a throat Mach number of 0.60 (fig. $10(\mathrm{~b})$ ), however, the trend is reversed with the minimum value of the static pressure and the greater initial adverse pressure gradient occurring for $a / b=1.5$. Thus, at the throat Mach number of 
0.45 , flow separation is more likely to occur on the lip with $2 / b=2.0$. But at 060 throat. Mach number separation is more likely to occur on the lip with $a / b=1.5$. However, it is not yet known why, at the lower throat Mach numbi: the minimum static pressure occurred for an inlet with $a / b=2.0$ but at th: higher throat Mach number, the minimum static pressure occurred for an t...et with $a / b=1.5$.

In addition to having an effect on the separation angle, changing the $a / b$ ratio also effects the total pressure recovery and distortion. This is shown in figure 11 as a function of throat Mach number for $0^{\circ}$ incidence angle at a freestream. velocity of 41 meters per second.

Both $a / b$ ratios show a general trend toward lower total pressure recovery and higher total pressure distortion levels with increasing throat Mach number. But at throat Mach numbers above about 0.6, the inlet lip with the lower $a / b$ ratio shows the greater decrease in pressure recovery and the larger increase in distortion level.

An explanation for the behavior at high throat Mach numbers can be given by examining the liffuser exit total pressure profiles shown in figure 12 . Results are presented for both $a / b$ ratios at a throat Mach number of 0.79 . The inlet with $a / b=1.5$ has a thicker boundary layer resulting in increased distortion and decreased pressure recovery. The boundary layer is thicker because the lip with the lower $a / b$ ratio has the lower minimum value of surface static pressure at this throat Mach number (see fig. 10(b)). This, in turn, increases the amount of overall diffusion resulting in the thicker boundary layer.

\section{Effect of Axial Location of Centerbody}

The effect of the axial location of the centerbody on the incidence angle at which internal flow separation occurs is shown in figure 13. The results are shown for throat Mach numbers of 0.30, 0.45, 0.60, and 0.7. As the figure indicates, the axial location of the centerbody has a large effect on the flow separation angle. The optimum location (1.e., the location that results in the maximum incidence angle before flow separation occurs) is a weak function of throat Mach number. At throat Mach numbers from 0.3 to 0.6, the optimum location for the centerbody is at about $(x / L)_{L E}=0.19$. This puts the leadingedge of the centerbody just downstream of the end of the inlet lip (as shown in the insert of fig. 13). At a throat Mach number of 0.70, the optimum location occurs when the centerbody is retrncted to $(x / L)_{L E}=0.376$.

Although the optimum axial location of the centerbody depends to some extent on throet Mach number, one single-fixed location that is very effective 
over the entire range of throat Mach numbers is at $(x / L)_{L E}=019$. With the centertody at this lowition, the inle'. "an achieve a significantly higher separation angle for throat. Mach numbers between 03 and 06 than can be achieved with the inlet using a shor centerbody (i.e., with the centerbody completrly retracted). Compared to the short centerbody, the maximum increase in the separation angle is $18^{\circ}$ and occurs at a throat Mach number of 0.45 .

In addition to having a large effect on the separation angle, the axial location of the centerbodv also affected where internal flow separation started (i.e., on the lip or in the diffuser) and how it behaved as shown by the open and closed symbols in figure 1.3 With the centerbody near its completely extended locations $\left(X,{ }^{\prime} L\right)_{L E} \leq 0.033$, flow separation started in the diffi ser and moved steadily forward as the incidence angle was incrcased. 'With the centerbody at the intermediate locations, $0.033<(x / L)_{L E}<0.4$, the flow separated instantaneously throughout the entire inlet.

This behavior can be clearly illustrated by examining the lip and diffuser separation detectors, $p_{l}$ and $\Delta P_{d}$, respectively, as a function of incidence angle. Traces of these are shown in figure 14 for a throat Mach number of 0.45 and for two axial locations of the centerbody. Also shown is the indicator of total pressure distortion, $\Delta P_{\text {dist }}$.

With the centerbody at, an intermediate axial location, $(x / L) L E=0.19$, both lip and diffuser separation indicators show an abrupt change at the same incidence angle of $73^{\circ}$ indicating that the flow separated instantaneously throughout the entire inlet. Thus the location of the start of separation could not be determined. But a reasonable assumption is that separation started on the lip. This is because less diffusion is required with the centerbody at this location than with the centerbody fully extended (see fig. 2(c-i)) and thus the lip is more likely to be the critical element. This type of separation resulted in a sharp incresse in distortion as shown by the abrupt increase in the distortion indicator at the incidence angle of $73^{\circ}$.

With the centerbody fully extended $(x / L)_{L}=-0.123$, the diffuser separetion indicator showed an abrupt decrease at an incidence angle of $41^{\circ}$ but the lip separation indicator showed no corresponding abrupt incresse. (The change in the If separation indicator at this incidence angle reflects the decrease in inlet airflow caused by diffuser separation.) As the incidence angle is increased from $41^{\circ}$, the separation point moves forward in the diffuser until at an incidence angle of $82^{\circ}$ separation occurs at the highlight. This is lllustrated in figure 16. The exial diftribution of internal static preseures on the inlet cowl is shown in figure 16(a) and the corresponding radial profile of total pressure at the diffuser extl is shown in figure 16(b). At $0^{\circ}$ incidence angle, the minimum static pressure occurs near the end of the inlet lip with a smooth 
cont inuous diffusion 'o the diffuser exit. The corresponding radial total pres sure profile shows no :vidence of flow separation. At an incide nee angle of $41^{\circ}$, diffuser separation has occurred at $\mathrm{x} / \mathrm{L}-0,32$ as indicated by the cow 1 stati pressure distribution which exhibits a downturn and a flat spot. The corresponding radial total-pressure profile clearly shows separated flow. At an incidence angle of $90^{\circ}$ (the nearest angle after separation at which data were taken), the flow has scparated a1, the highlight since the cowl static pressure distribution is flat throughout the entire inlet. The corresponding radial totalpressure profile shows a large separated region extending over about $\mathbf{5 0}$ perrent of the duct height

The increase in distortion associated wir. diffuser separation is less severe than that which occurred when the flow separated instantaneously throughout the inlet. This can be scen by referring back to figure 14 . The disturtion indicalor increased to about 0.05 when diffuser separation occurred compared to a value of 0.16 when the flow separated instantaneously. As previously mentioned, the distortion associated with instantaneous separation might be severe enough to cause excessively high fan blade stresses and/or a large loss in engine thrust thus precluding the possibility of operating the fan in separated flow. However, the distortion associated with di...ser separation is less severe so that the fan blade stresses might be sufficiently low and the loss in thrust might not be too much. This would allow the fan to operaie in separated flow. Thus, at axial locations of the centerbody where diffuser separation occurs, the inlet engine combination might be able to operate at even higher incidence angles than shown by the solid symbols in figure 13.

When the centerbody is near its completely retracted position, the location where separation starts depends on the throat Mach number. At the lower throat Mach numbers $(0.30$ and 0.45$)$, separation starts in the diffuser as indicated by the solid symbols. At the higher throat Mach numbers $; 0.60$ and 0.70 ), separation probably starts on the lip as indicated by the open symbols. The reason for this behavior is not yet known.

\section{Relative Effectiveness of Geometric Veriablee}

The effectiveness of inlets incorporating the three geometric variables previously discussed is compared in figure 16 for two values of inlet throut Mach number. At both throat Mach numbers $(0.45$ and 0.70$)$ the moat effective inict in terms of bigh incidence angle capablility was the one that incorporated 2 centerbody located at $(x / L)_{L E}=0.19$ (the le. Ins edye of the centerbody is located near the end of the inlet lip). At a throut March number of 0.45 (fig. $16(a)$ ), this inlet configuration, which had a contraction ratio of 1.46 , achieved 
an incidence angle of $73^{\circ}$ before internal flow separation occurred. In comparison, an inlet configuration with a conventional short centerbody required a contraction ratio of about 1.7 to achieve the same incidence angle before the flow separated. Hence, incorporating this centerbody in an inlet is equivalent to a substantial increase in the inlet contraction ratio.

At a throat Mach number of 0.7 (fig. 16(b)), this same centerbody position $\left((x / L)_{L E}=0.19\right)$ improved the incidence angle capability of a 1.46 contraction ratio inlet to the point where it was equivalent to a 1.55 contraction ratio inlet with a conventional short centerbody. The higher contraction ratio inlet would result in an increase in the nacelle maximum diamster (for the same inlet design throat Mach number) wh, ch, in turn, would increase the nacelle weight. The drag at cruise conditions also wonld be increased.

The inlet with the centerbody located at $(x / L)_{L E}=0.19$ also achieved a higher separation angle than could be achieved by either of the two $a / b$ ratio inlets with conventional short centerbodies. For a contraction ratio of 1.46 at 0.45 'hroat Mach number (fig. 16(a)), the separation angle could be increased $9^{\circ}$ compared to an inlet with an $\mathrm{a} / \mathrm{b}$ ratio of 1.5 and a conventional short centerbody. At 0.70 throat Mach number and the same contraction ratio (fig. 16(b)), the separation angle could be increased $5^{\circ}$ compared to an inlet with an $\mathrm{a} / \mathrm{b}$ ratio of 2.0 and a conventional short centerbody. As previously mentioned, the inlet with $\mathrm{a} / \mathrm{b}$ ratio of 1.5 had a higher separation angle than the inlet with $\mathrm{a} / \mathrm{b}$ ratio of 2.0 at 0.45 throat Mach number but at 0.7 throat Mach number the reverse occurred as indicated in the figure.

\section{SUMMARY OF RESULTS}

Engine inlets for tilt-nacelle VTOL aircraft must operate over a wide range of incidence angles without internal flow separation. Scale model inlets were tested in the NASA Lewis $2.74-$ by 4.58 -meter (9-by 15-ft) Low Speed Wind Tunnel to evaluate the effectiveness of three geometric variables + provide this capability. The three geometric variables were (1) internal lip contraction ratio, (2) internal lip major-to-minor-axis ratio, and (3) location of the centerbody within the cowl. Free-stream velocity was 41 meters per second. Inlet average throat Mach number was varied between 0.30 and 0.79 . The results of the study may be summarized as follows:

1. Increasing the internal lip contraction ratio increased the incidence angle at which flow separation occurred. For a contraction ratio of 1.37 , the maximum value for this angle was $61^{\circ}$. For a contraction ratio of 2.0, the mwximum value was greater than $150^{\circ}\left(160^{\circ}\right.$ was the largest incidence angle that could be achieved in the facility). 
2. Decreasing the internal lip major-to-minor-axis ratio from 2.0 to 1.5 $w$ ith an inlet contraction ratic of 1.46 had a beneficial effect on the separation angle at low throat Nach numbers but an adverse effect at high throat Mach numbers. Below a throat Mach number of 0.57 , the separation angle was increased by abcut ${ }^{\circ}$; above this throat Mach number, the separation angle was decreased by as much as $33^{\circ}$. Also above this throat Mach number, there was a significant reduction in the aerodynamic performance (i.e., decreased pressure recovery and increased distortion) for the major-to-minor-axis ratio of 1.5 .

3. The axial location of the enterbor. had a large effect on the separation angle. Translating the centerbody from its completely ret racted location to the location where its leading edge was just downstream of the end of the inlet lip resulted in increasing the separation angle by as much as $10^{\circ}$.

4. The axial lucation of the centerbody affected the behavior of flow separation. With the centerbody near its fully extended or retracted locations, flow separation generally started in the diffuser and then moved forward as the incidence angle was increased. At the other centerbody locations, the flow separated instantaneously throughout the entire inlet.

5. Incorporating a centerbody with its leading edge located just downstream of the end of the inlet lip was equivalent to substantially increasing the inlet contraction ratio. At 0.45 throat Mach number, the effective contraction ratio of the inlet was increased from 1.46 to 1.7 compared to an inlet with a conventional short centerbody.

6. With the centerbody at this location, the inlet could achieve a higher separation angle than could be achieved by either of the two $a / b$ ratio inlets that had conventional short centerbodies. At 0.45 throat Mach number, the separation angle could be increased by as much as $9^{\circ}$.

\section{REFERENCES}

1. Albers, J. A., and Miller, B. A., "Effect of Subsonic Inlet Lip Geometry on Predicted Surface and Flow Mach Number Distributions, " NASA TN D-7446, 1973.

2. Alters, J. A., Stockman, N. O., and Hirn, J. J., "Aerodynamic Analysis of Several High Throat Mach Number Inlets for the Quiet, Clean, Short-Haul Experimental Engine," NASA TM X-3183, 1975.

3. Boles, M. A., Luidens, R. W., and Stockman, N. O., "Theoretical Flow Characteristics of Inlets for Tilting-Nacelle VTOL Aircraft, " NASA TP-1205, 1978. 
4. Jakubowski, A. K., and Luidens, R. W., "Internal Cowl-Separation at High Incidence Angles," AIAA Paper 75-64, Jan. 1975.

5. Miller, B. A., Dastoli, B. J., and Wesoky, H. L., "Effect of Entry-Lip Design on Aerodynamics and Acoustics of High Throat Mach Number Inlets for the Quiet, Clean, Short-Haul Experimental Engine," NASA TM X-3222, 1975 .

6. Miller, B. A., "Inlets for High Angles of Attack, " Journal of Aircraft, Vol. 13, Apr. 1976, pp. 319-320.

7. Miller, B. A., "Effect of Design Changes on Aerodynamic and Acoustic Performance of Translating Centerbody Sonic Inlets, " NASA TP-1132, 1978.

8. Yuska, J. A., Diedrich, J. H., and Clough, N., "Lewis 9- By 15-Foot V/STOL Wind Tunnel, " NASA TM X-2305, 1971. 
TABLE: I - SIMMARY OF INLET FIXED GEOMETRIC PARAMETERS

(a) Diffuser

\begin{tabular}{|c|c|c|}
\hline Parameter & $\begin{array}{c}\text { High } \\
\text { contraction } \\
\text { ratio } \\
\text { configurations }\end{array}$ & $\begin{array}{c}\text { Translating } \\
\text { centerbody } \\
\text { configurations }\end{array}$ \\
\hline $\begin{array}{l}\text { Ratio of exit ilow area to throat area, } \\
\left(D_{\mathrm{e}}^{2}-\mathrm{D}_{\text {hub }}^{2}\right) / \mathrm{D}_{t}^{2}\end{array}$ & 1.21 & Variable \\
\hline $\begin{array}{l}\text { Ratio of diffuser length to exit diameter, } \\
\mathrm{L}_{\mathrm{d}} \cdot \mathrm{D}_{\mathrm{e}}\end{array}$ & 0.826 & 0.875 \\
\hline Diffuser exit diameter ratio, $\mathrm{D}_{\mathrm{hub}} / \mathrm{D}_{\mathrm{e}}$ & 0.40 & 0.40 \\
\hline Maximum $x$ all angle, $\theta_{\max }$, deg & 8.7 & 10.7 \\
\hline Equivalent conical half-angle, $\lambda$, deg & 2.9 & Fig. $2(c-2)$ \\
\hline $\begin{array}{l}\text { Location of maximum wall angle, } \\
\text { percent } L_{d} \text {, downstream of throat }\end{array}$ & 50 & 26 \\
\hline Surface contour & Cubic & $\begin{array}{l}\text { Two super- } \\
\text { ellipses }\end{array}$ \\
\hline
\end{tabular}

(b) Centerbody

Ratio of length to diameter, $\mathrm{L}_{\mathrm{cb}} / \mathrm{D}_{\text {hub }}$

Axial location of centerbody leading edge for high contraction ratio configurations, percent $L_{d}$, downstream of throat

Axial location of centerbody leading edge for translating centerbody configurations, $(\mathrm{x} / \mathrm{L})_{\mathrm{LE}}$

Surface contour

Ratio of maximum diameter to hub diameter, $D_{c b} / D_{\text {hub }}$

Ratio of aftbody length to maximum diameter, $\mathrm{g} / \mathrm{D}_{\mathrm{cb}}$

Ratio of forebody length to maximum diameter, $e / D_{c b}$ Aftbody surface contour Forebody surface contour

\subsection{5 \\ 63.7}

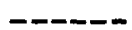

Fig. 2(c-1)

Ellipse

1.125

0.741

0.75

Cubic Superellipse 

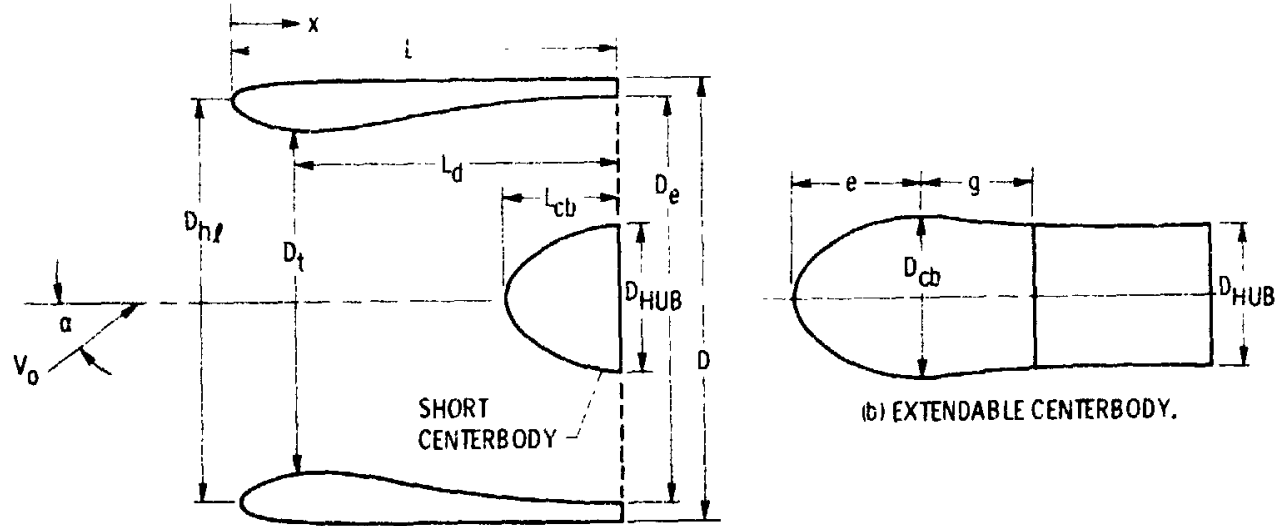

(a) INLET.

Figure 1. - Nomenclature.

ڤ్

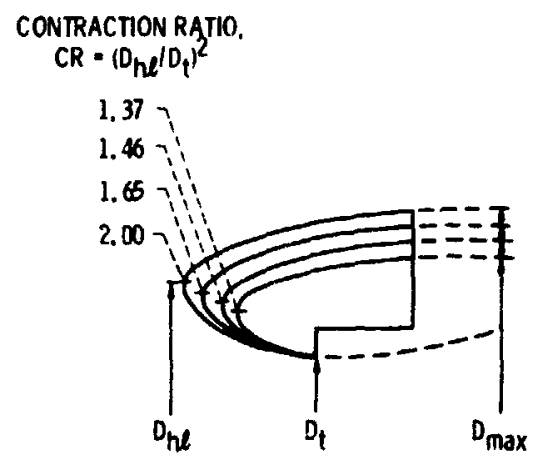

$\mathrm{a} / \mathrm{b}$

1.57

2.07

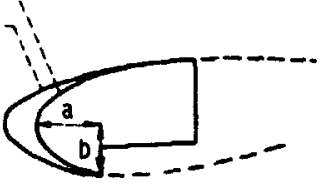

(D) MAJOR-TO-MINOR AXIS RATIO VARIATIONS, $C R=1.46$,

(a) CONTRACTION RATIO VARIATIONS,

$a / b=2.0$.

Figure 2. - Lip and centerbody geometric variables.
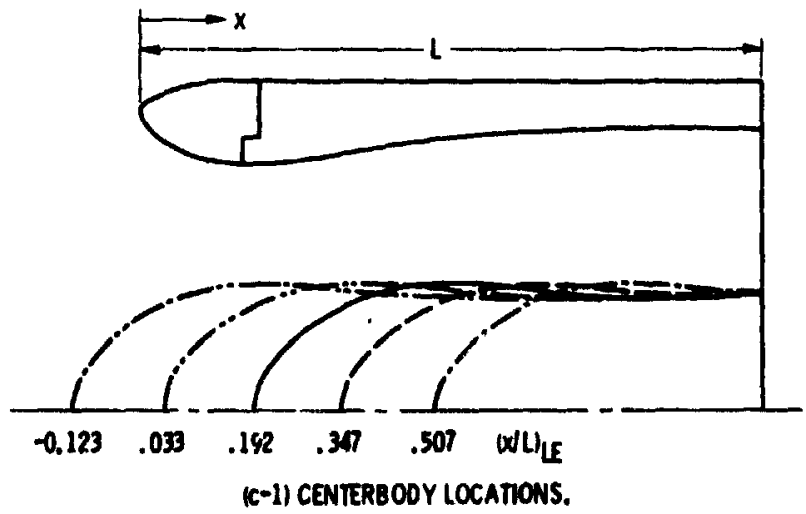

(C) CENTERBODY VARIATONS, CR -1.46 a

Figure 2 - Continued. 


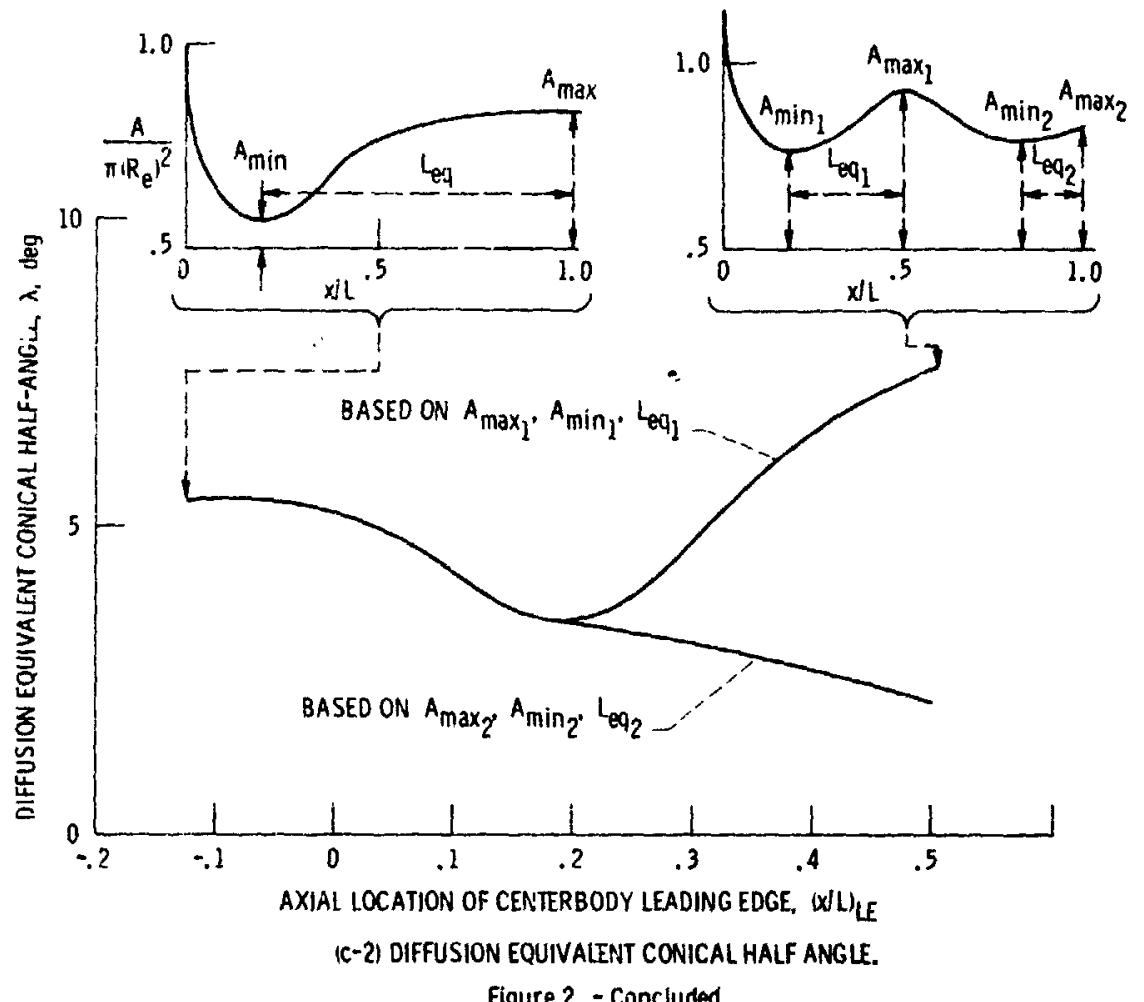

figure 2. - Concluded.

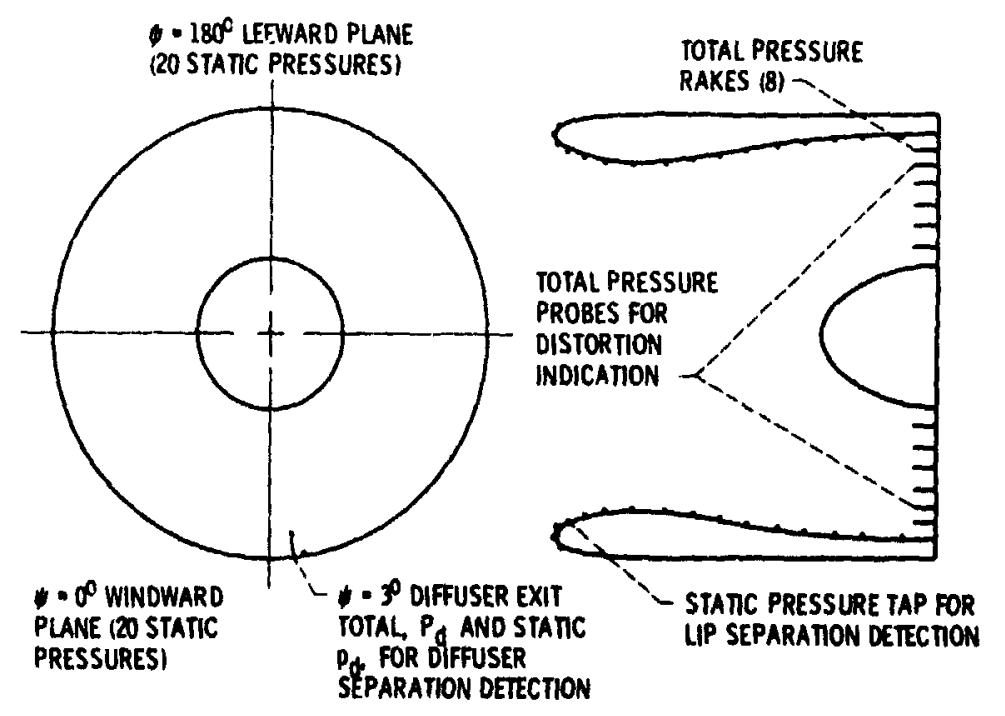

Figure 3. - Instrumentation locations. 
$\stackrel{0}{0}$

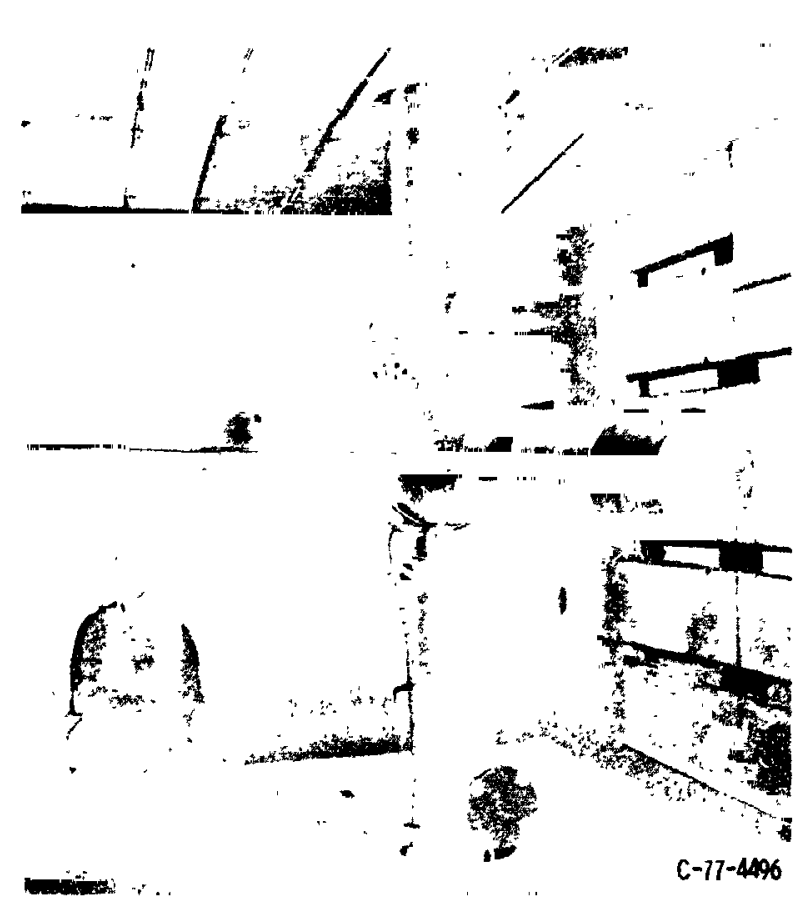

GINAL PAOE POE IS
PUALITY

Figure 4. - Installation of model inlet in V/STOL wind tunnel.

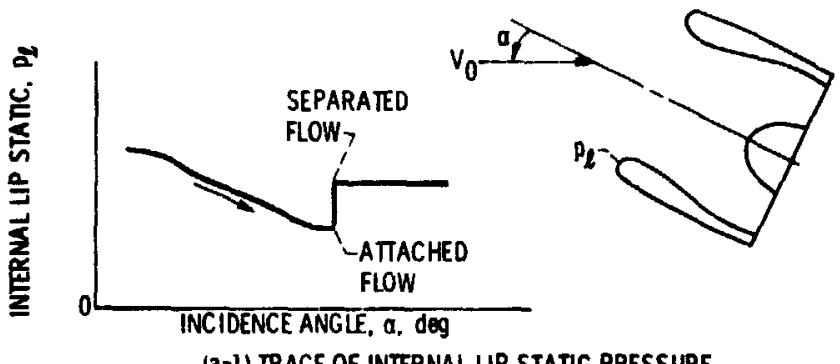

(a-1) IRACE OF INTERNAL LIP STATIC PRESSURE.

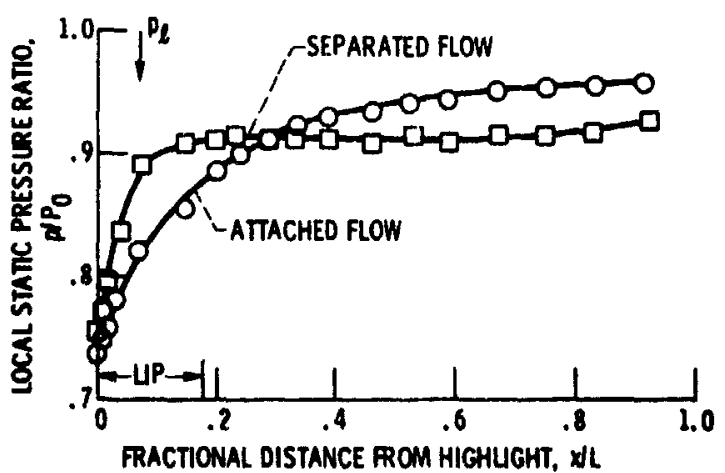

(a-2) WINOWARD SURFACE STAIIC PRESSURE DISTRIBUnow.

(a) INLET LIP SEPARATHON.

Flgure 5. - Separation detuction. 


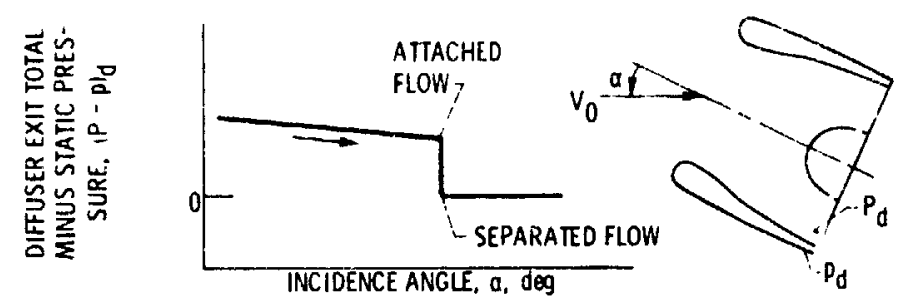

(b-1) TRACE OF DIFFUSER EXIT TOTAL MINUS STATIC.

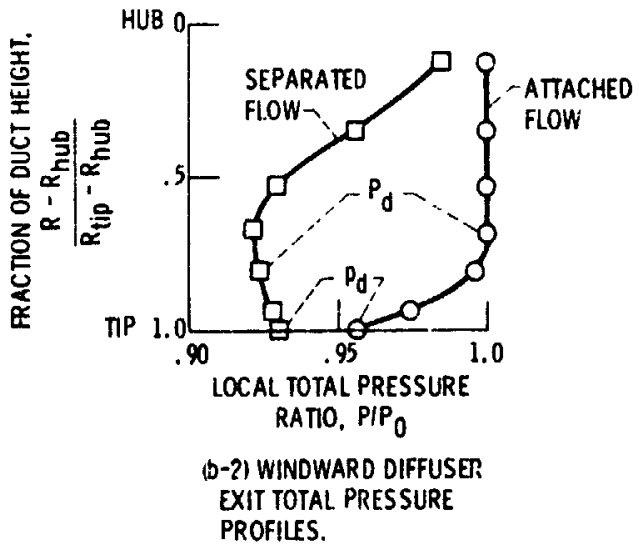

(b) DIFFUSER EXIT SEPARATION.

Figure 5. - Concluded.

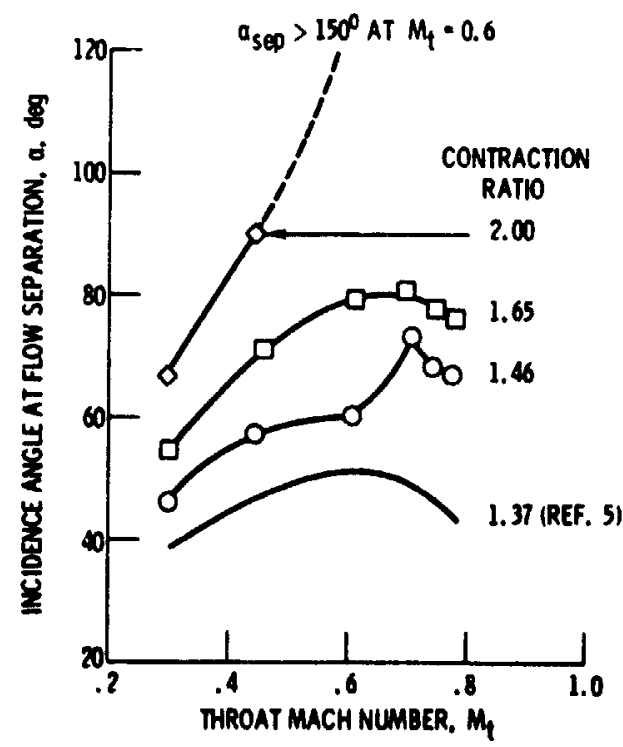

Figure 6. Effect of lip contraction ratio on separation bounds. $V_{0}=41$ metors pwr second $1 b \cdot \mathbf{2 . 0}$. 


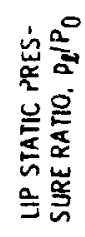
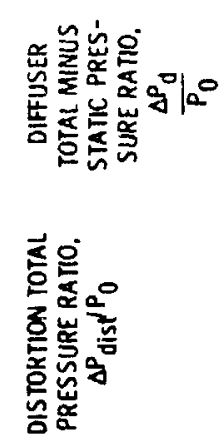

它
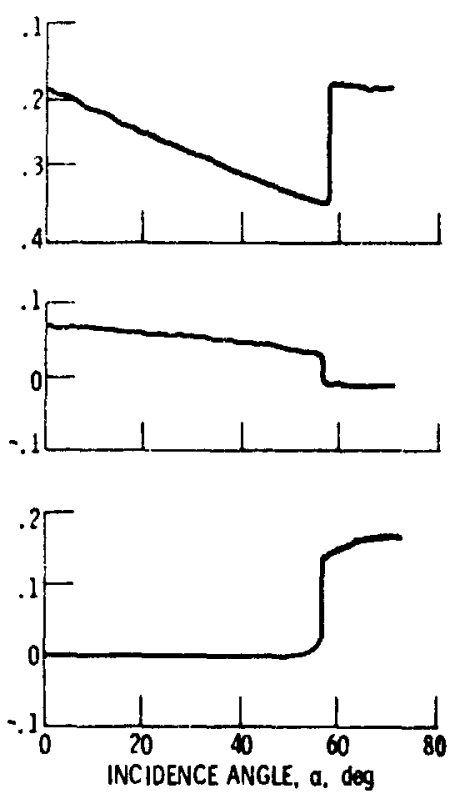

Figure 7. - Separation behavior. CR . 1.46, $\mathrm{a} / \mathrm{b}=2 . \mathrm{Q}, M_{\mathrm{t}}=0.45, V_{0}=41$ meters per second.

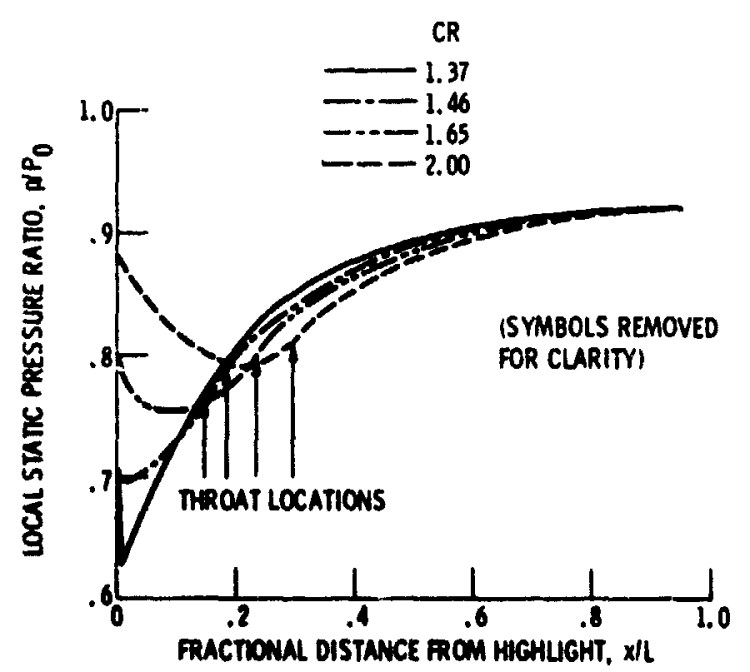

Floure 8. - Effict of lip contraction ratto on windurerd surbee stutic pressure distribution, $a=300_{i} V_{0}=$ 4 meters per second $a b=2 . Q . M \cdot Q .6$.

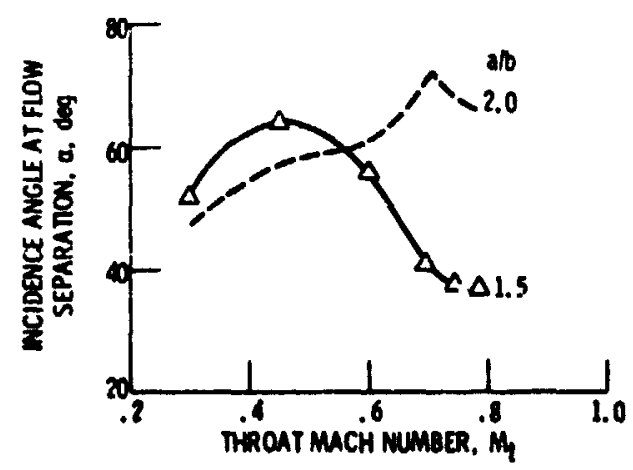

Figure 9. - Eficet of lip ab ratio on semerntion bounds. $V_{0}=4$ motwe ser scoond $C R=1.46$ 


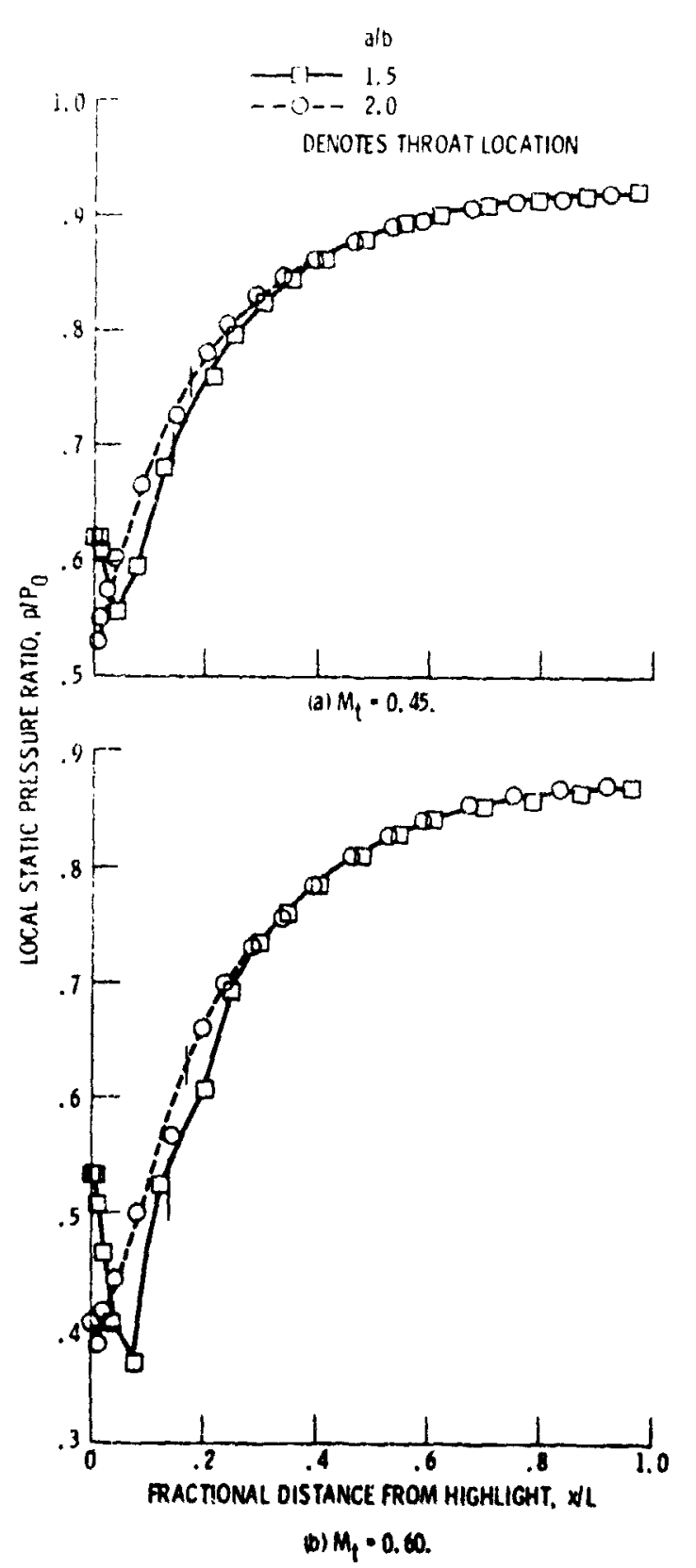

Figure 10. - Eflect of alo ratio on winoward surface static pressure proflic. a $-500_{i} V_{0}=41$ meters Der second $C R=1.46$.
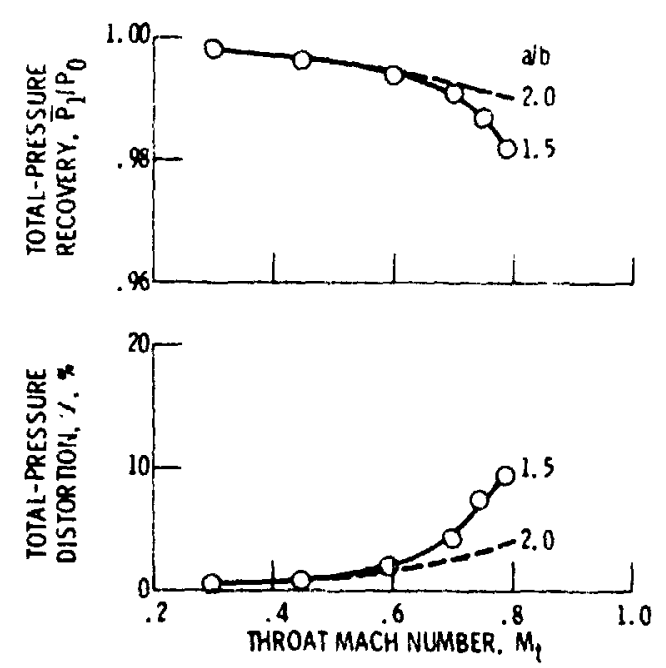

Figure 11. - Effect of lip ato ratio on aerodynamic pertormance. $V_{0}=4$ meters per second; $a=0^{\circ}$; $C R=1.46$.

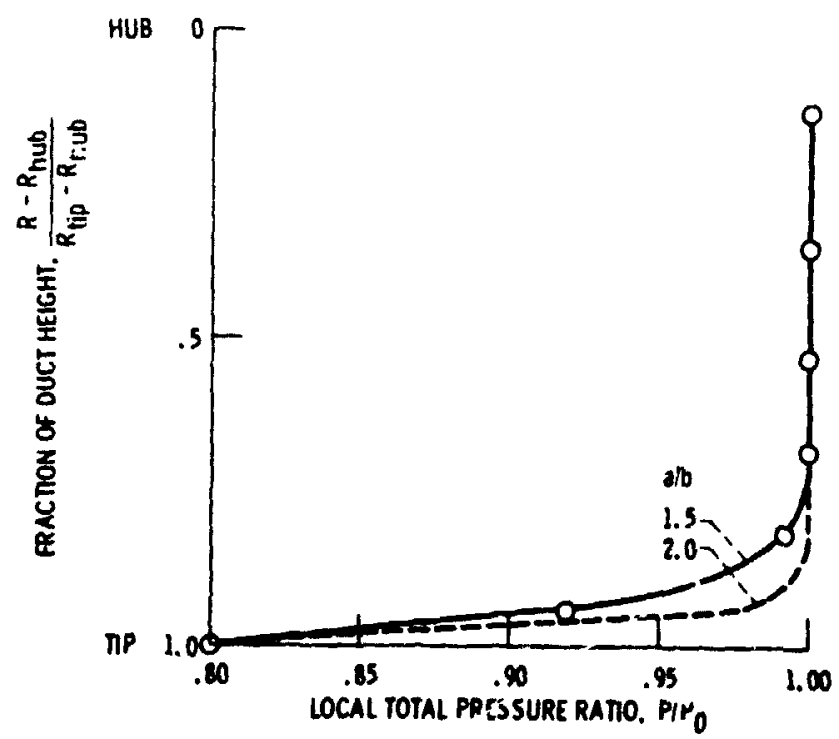

Figure 12. - Effect of lip ab ratio on diffuser exit byal pressure prefile. $V_{0}=0$ meters per second $a-0_{i}$ $M \cdot 0 . m$ CR 1.1 


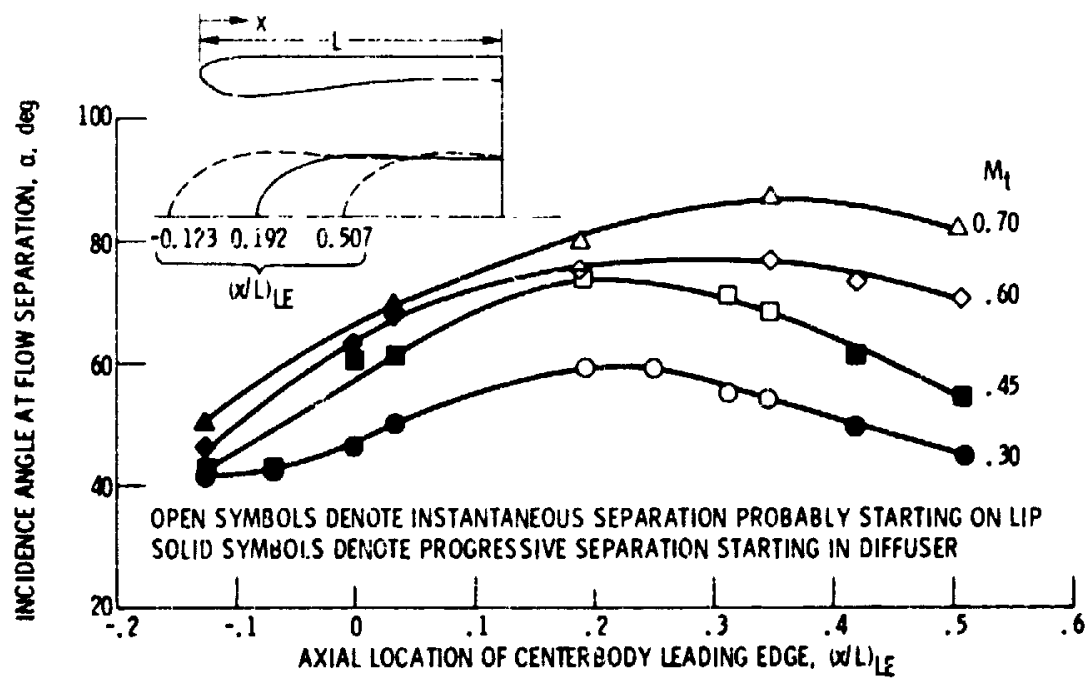

Figure 13. - Effect of centerbody location on separation bounds. $V_{0}=41$ meters per second: $C F \cdot 1.46, a / b \cdot 2.0$.

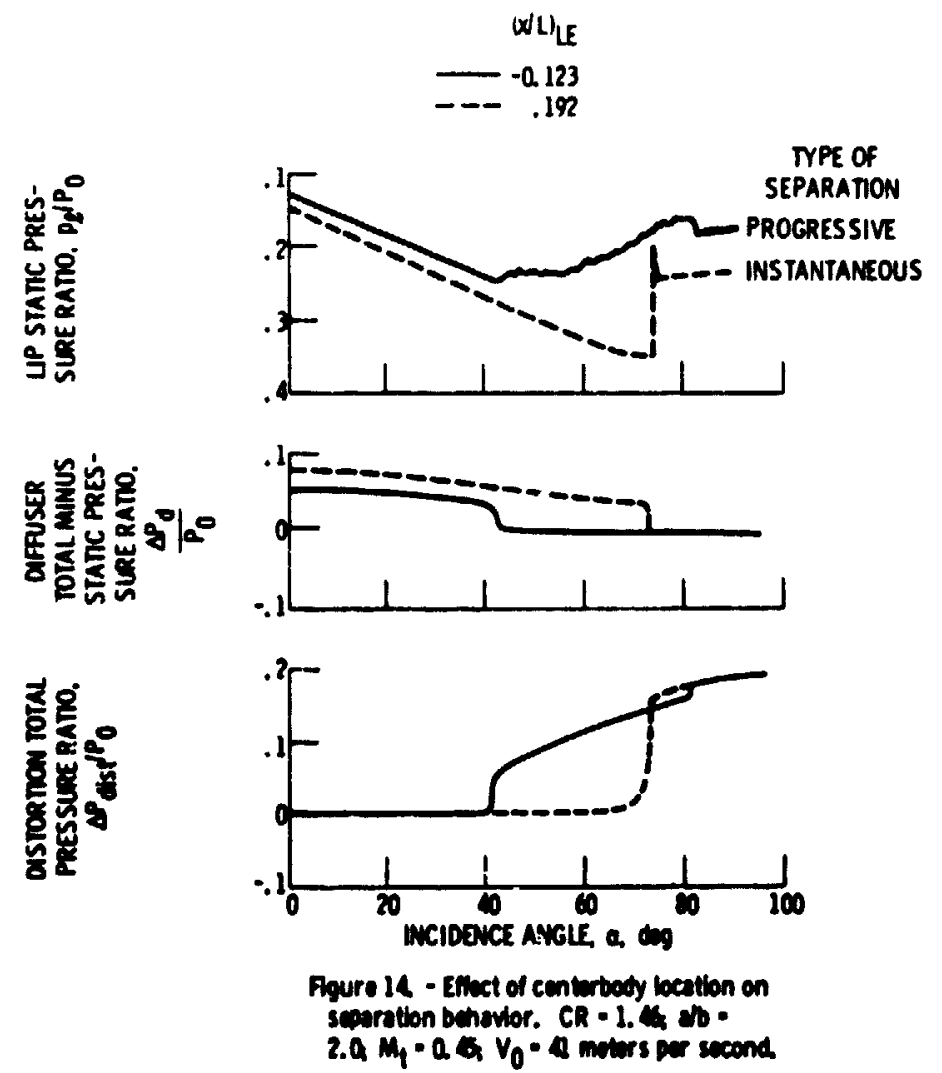



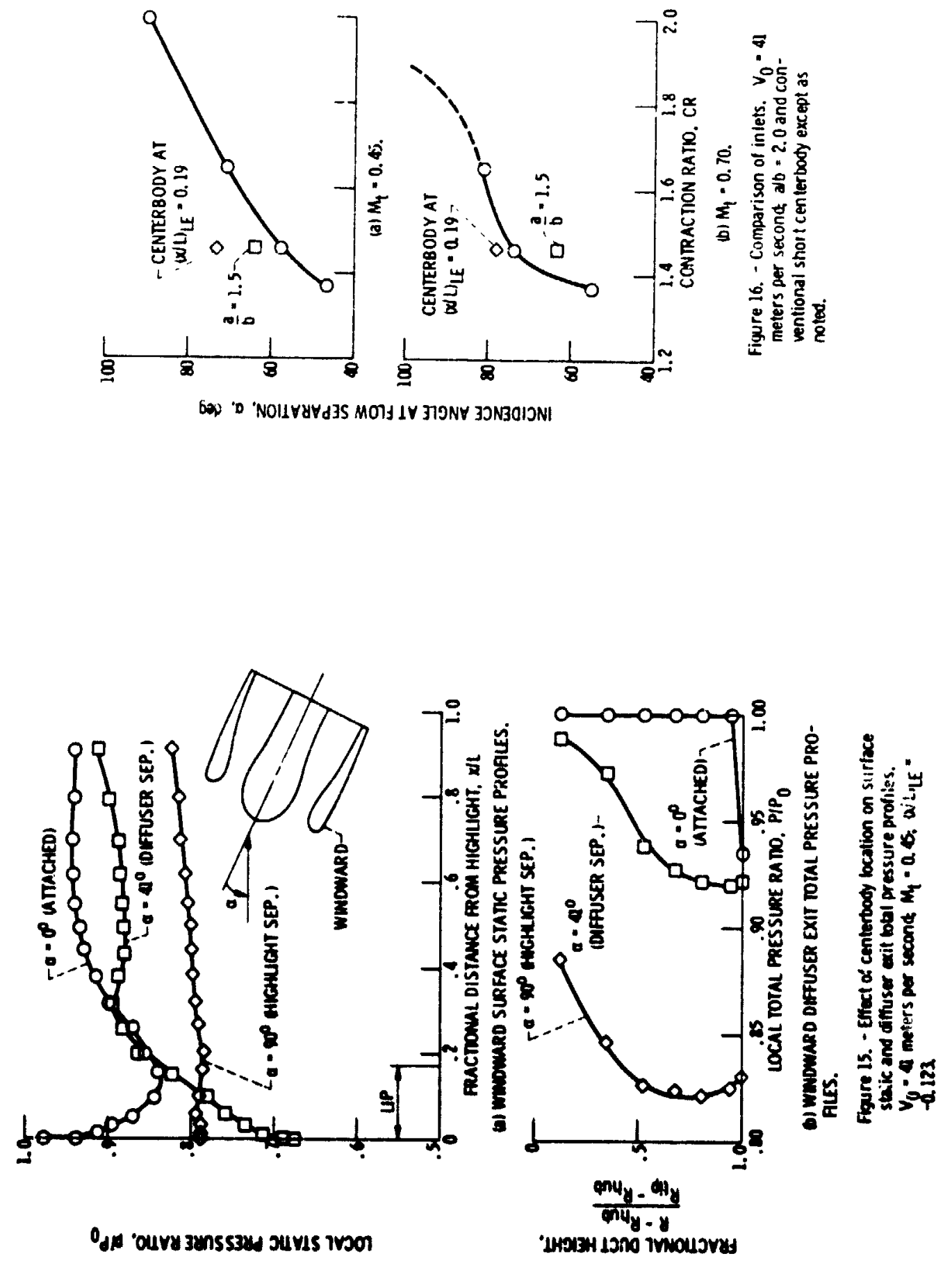